Article

\title{
Effect of Cooling Rate on Microstructure and Properties of Twin-Roll Casting 6061 Aluminum Alloy Sheet
}

\author{
Zhen $\mathrm{Xu}{ }^{1, *}$, Sixue Wang ${ }^{1}$, Hongbin Wang ${ }^{1, *}$, Hua Song ${ }^{2}$, Shengli $\mathrm{Li}^{1}$ and Xingyu Chen ${ }^{3}$ \\ 1 School of Materials Science and Metallurgy, University of Science and Technology Liaoning, No. 185, \\ Qianshan Middle Road, Lishan District, Anshan 114051, China; wangsx5200@163.com (S.W.); \\ lishengli@sohu.com (S.L.) \\ 2 School of Mechanical Engineering and Automation, University of Science and Technology Liaoning, No. 185, \\ Qianshan Middle Road, Lishan District, Anshan 114051, China; songhua88@126.com \\ 3 Anshan Zizhu Sci. \& Tech.Profile Steel Co., Ltd., Anshan 114015, China; twchenxingyu@163.com \\ * Correspondence: ustlxuzhen@126.com (Z.X.); whb605@163.com (H.W.); \\ Tel.: +86-041-2592-9535 (Z.X.); +86-041-2592-9563 (H.W.)
}

Received: 2 July 2020; Accepted: 11 August 2020; Published: 30 August 2020

\begin{abstract}
In this study, a twin-roll casting sheet of 6061 aluminum alloy was cooled using furnace, asbestos, air, wind and water. The effect of cooling rate on the microstructure and properties of twin-roll casting 6061 aluminum alloy sheet were studied. Optical microscope, scanning electron microscope, X-ray diffraction, microhardness tester and universal tensile machine were used to observe the microstructure and properties of twin-roll casting sheet of 6061 aluminum alloy. The results show that the higher the cooling rate, the smaller the grain size of the alloy and the smaller the number of precipitated phases in the matrix. Uniform grain size of the alloy could be obtained at a stable cooling rate. The hardness, tensile strength and elongation of the twin-roll casting sheet increased with cooling rate. Under wind cooling condition, the twin-roll casting sheet demonstrated excellent comprehensive performance, i.e., $88 \mathrm{MPa}$ of yield strength, $178 \mathrm{MPa}$ of tensile strength and $15 \%$ of elongation, respectively. A quantitative Hall-Petch relation was established to predict the yield strength of 6061 twin-roll casting sheets with different grain sizes and cooling rate.
\end{abstract}

Keywords: cooling rate; aluminum alloy 6061; twin-roll casting; microstructure; mechanical properties

\section{Introduction}

Over the last decades, increasing demand for lightweight materials from multiple industrial applications motivates researchers to focus on aluminum alloys [1-3].

The Al-Mg-Si series (6XXX series) alloy is one of the forged aluminum alloys in which $\mathrm{Mg}$ and $\mathrm{Si}$ can form main strengthening phase $\mathrm{Mg}_{2} \mathrm{Si}$ [4]. This series of alloys have the advantages of medium-high strength, good corrosion resistance, excellent welding ability, high plasticity, as well as good processing properties after heat treatment. As a result, it can be widely used in forging, rolling, stamping, and other processes [5-7]. Up to now, Al-Mg-Si aluminum alloy has been applied comprehensively in aerospace, automobile manufacturing, electronic home appliances, and other fields [8,9]. The twin-roll casting (TRC) process is that molten metal is poured, solidified, and plastic deformed in a short time through a pair of rotating casting rolls as the crystallizer, and then directly turns into a thin metal strip [10]. The twin-roll casting process combines two processes of sub-rapid solidification and hot-working, greatly shortening production process, and the corresponding products with fine microstructure could possess greater strength and hardness [11,12]. Therefore, the twin-roll casting (TRC) process is becoming 
a more and more efficient and vital part of aluminum alloy processing technology, especially for Al-Mg-Si series (6XXX series) alloy.

During the solidification and cooling process, the cooling rate, one of the critical parameters, directly affects product performance. In recent years, numerous researchers have conducred a great amount of research in this field. S.G. Shabestari [13] reported that a higher cooling rate would significantly decrease the size of Dendrite Arm Spacing, the recalescence undercooling temperature, and total solidification time, and increase the liquidus temperature, nucleation undercooling temperature, and solidification range. B. Benjunior et al. [14] studied the effect of different cooling rate conditions on thermal profile and microstructure of aluminum 6061, indicating that different cooling rate conditions will alter the material phase change temperatures. Furthermore, cooling rate was performed to reduce the porosity by reducing the size of Dendrite Arm Spacing [15], which influences mechanical properties to some extent.

In the roll-casting process, there are many factors that affect microstructure and properties of the cast strip [16]. Studies show that cooling rate affects the microstructure and mechanical properties of aluminum alloy twin-roll casting sheets, but few researchers studied the effect of post-rolling cooling rate on the microstructure and properties of cast-roll 6061 aluminum alloy sheets [17,18].

Based on this, this paper selects twin-roll casting and rolling 6061 aluminum alloy sheets as the research target, and introduces five different cooling methods, i.e., furnace cooling, asbestos covering, air cooling, wind cooling, and water cooling. The aims are to study the influence of cooling rate on the microstructure and mechanical properties of 6061 aluminum alloy twin-roll casting sheets, obtain a reasonable cooling method and related process parameters, and further optimize the microstructure and mechanical properties of twin-roll casting 6061 aluminum alloy. In the final, the Hall-Petch (H-P) relation between yield strength and grain size is investigated.

\section{Experimental Procedures}

The commercial 6061 aluminum alloy was selected as the experimental material, and its chemical composition is shown in Table 1. Experiment was carried out on a horizontal twin roll caster with a roll diameter of $\varphi 130 \mathrm{~mm}$. The 6061 aluminum alloy ingot was heated and smelted in a box type SX2-10-12 resistance furnace (Shenyang GE Furnace Co. LTD, Shenyang, China), and the heating temperature was $710 \pm 5^{\circ} \mathrm{C}$. After the alloy was completely melted and stirred uniformly, it was kept in a heating furnace for $10 \mathrm{~min}$. Then, the temperature was lowered to $690 \pm 5^{\circ} \mathrm{C}$, and the molten metal was transferred to a twin roll caster for twin-roll casting test, and it was cast and rolled into sheets with a thickness of $1.5 \mathrm{~mm}$. The twin-roll casting sheets were cooled at different cooling rates. The cooling rate was achieved using five methods: furnace cooling, asbestos covering, air cooling, air cooling, and water cooling.

Table 1. Chemical composition of 6061 aluminum alloy.

\begin{tabular}{cccccccccc}
\hline Composition & $\mathbf{M g}$ & $\mathrm{Si}$ & $\mathbf{C u}$ & $\mathbf{C r}$ & $\mathbf{F e}$ & $\mathbf{M n}$ & $\mathrm{Zn}$ & $\mathrm{Ti}$ & $\mathrm{Al}$ \\
\hline wt $\%$ & 0.834 & 0.594 & 0.194 & 0.051 & 0.182 & 0.028 & 0.023 & 0.016 & 98.078 \\
\hline
\end{tabular}

The twin-roll casting sheet was cut into small pieces by a electric discharge wire cutting machine. The specimens were ground and polished, and then etched with Keller reagent $(2.5 \mathrm{~mL} \mathrm{HNO}+1.5 \mathrm{~mL}$ $\mathrm{HCL}+1 \mathrm{~mL} \mathrm{HF}+95 \mathrm{~mL} \mathrm{H}_{2} \mathrm{O}$ in volume) for $15 \mathrm{~s}$, and the microstructure was observed using a ZEISS optical microscope (Jena, Germany). The sample was subjected to X-ray diffraction analysis using an X-ray diffraction (XRD, $X^{\prime}$ Pert Powder). The mechanical properties were measured at room temperature $\left(20^{\circ} \mathrm{C}\right)$ using an electrohydraulic servo material testing machine (UTM5305, HST, Jinan, China) with a tensile speed of $1 \mathrm{~mm} / \mathrm{min}$ based on Chinese standards (GB/T 228-2002). The dimensional drawing of tensile specimens, which were cut by electric discharge machine from different positions of the cladding billet, is show in Figure 1. Field emission high-resolution scanning electron microscopy 
(SEM) was used to observe the fracture morphology and analyze the size and distribution of the phases. The phase composition was determined using a companion spectrometer. The surface of the sample was ground to a bright light, and the hardness was measured using a Vickers hardness tester (Qness Q10M) with a test load of $3 \mathrm{~N}$ and a dwell time of $15 \mathrm{~s}$. In addition, all the test results were averaged from three effective values.

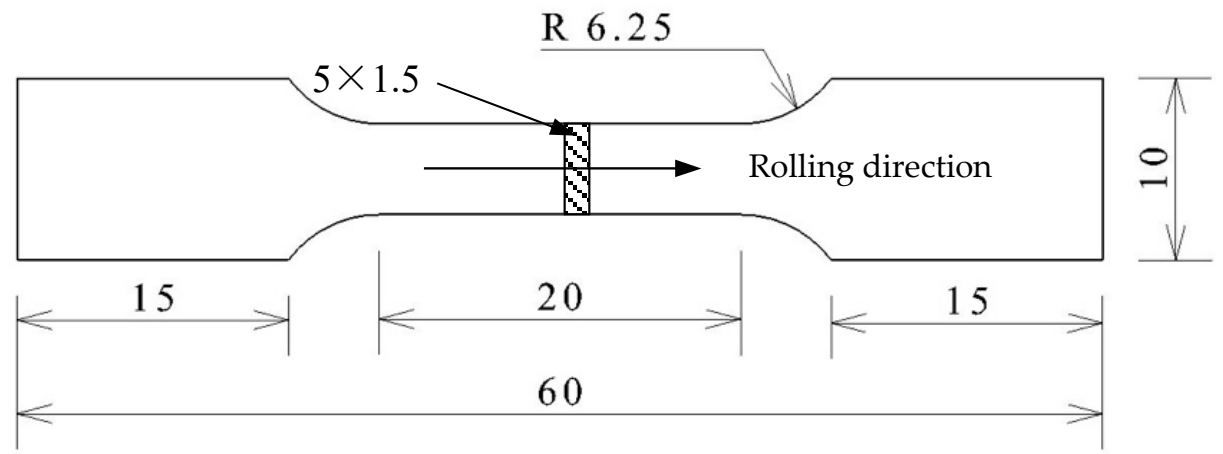

Figure 1. Dimensional drawing of tensile specimens (all dimensions are in $\mathrm{mm}$ ).

\section{Result and Discussion}

\subsection{Determination of Cooling Rate}

The 6061 aluminum alloy twin-roll casting sheet was cooled by five different cooling methods, and the cooling rate was measured using a thermocouple [19]. A plot of slab temperature versus time for different cooling modes was plotted, and the first derivative plot was calculated from the obtained cooling curves, as shown in Figure 2.

The 6061 aluminum alloy twin-roll casting sheet was placed in a furnace to achieve slow cooling, and the average cooling rate was $0.006^{\circ} \mathrm{C} / \mathrm{s}$. Figure $2 \mathrm{a}$ shows the temperature change curve under slow cooling and the derivative curve of temperature changing, i.e., the cooling rate curve. The furnace cooling rate appeared to be the slowest and gradually decreased when the furnace temperature approached room temperature.

Relatively slow cooling was achieved by covering the 6061 aluminum alloy twin-roll casting sheet with asbestos, with an average cooling rate of $0.2{ }^{\circ} \mathrm{C} / \mathrm{s}$. The temperature/time relationship is shown in Figure $2 b$. It can be seen that the $d_{T} / d_{t}$ curve exhibits a straight line parallel to the horizontal axis. The overall cooling rate in this cooling mode tends to be uniform, and the cooling rate appears to be slower.

Figure 2c shows the temperature change curve and cooling rate curve for air cooling of the twin-roll casting 6061 aluminum alloy sheet. It took about $275 \mathrm{~s}$ for the twin-roll casting sheet to naturally cool to room temperature $\left(25 \pm 1^{\circ} \mathrm{C}\right)$ in air, and the average cooling rate was $2.4^{\circ} \mathrm{C} / \mathrm{s}$.

The twin-roll casting 6061 aluminum alloy sheet was cooled relatively quickly by a blower to accelerate the air flow, and the average cooling rate was $3{ }^{\circ} \mathrm{C} / \mathrm{s}$. Figure $2 \mathrm{~d}$ shows the temperature profile and cooling rate curve for this cooling condition. The trend of cooling rate changed during wind cooling in a similar way to air cooling. However, the cooling rate at high temperatures for wind cooling was greater than that of air cooling, and the cooling rate was more stable. The maximum cooling rate condition was achieved by the method of water cooling. The twin-roll casting sheet was immediately placed in water, and the twin-roll casting sheet was taken out from the water after the temperature cooled to room temperature.

The temperature change curve and the cooling rate curve obtained under the water cooling condition are shown in Figure 2e. As can be seen from the figure, when the slab was immersed in water, the cooling rate was largest and could be maintained for about $12 \mathrm{~s}$. When the sheet was cooled to about $50{ }^{\circ} \mathrm{C}$, the cooling rate remained substantially unchanged, and the average cooling rate of the water cooling process was $21.3^{\circ} \mathrm{C} / \mathrm{s}$. 
(a)

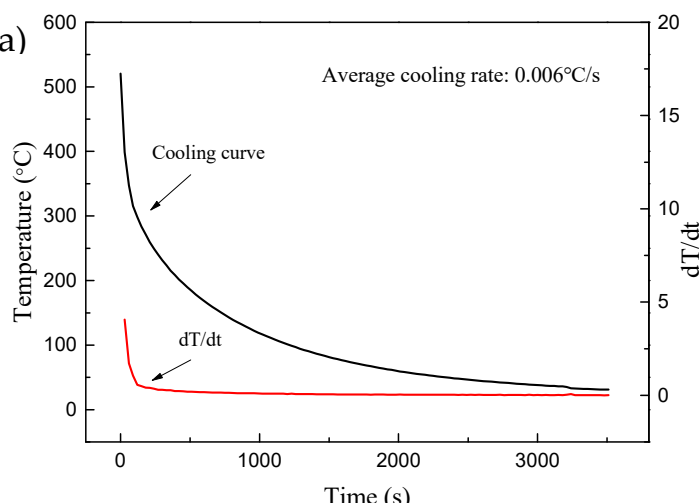

(c)

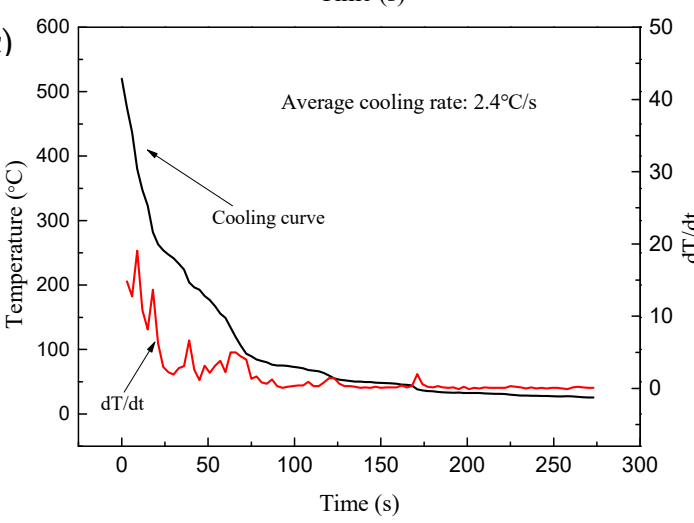

(b)

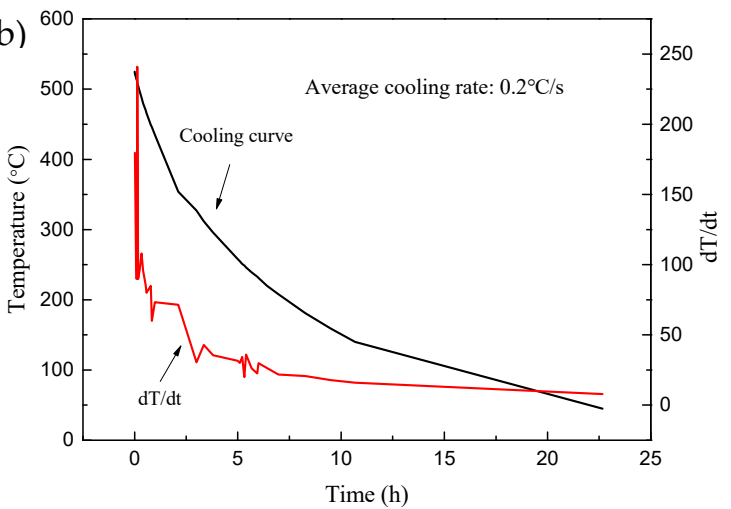

(d)

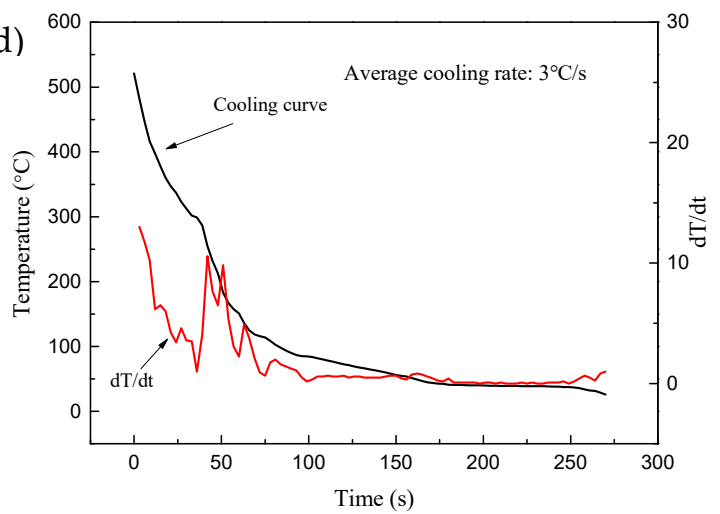

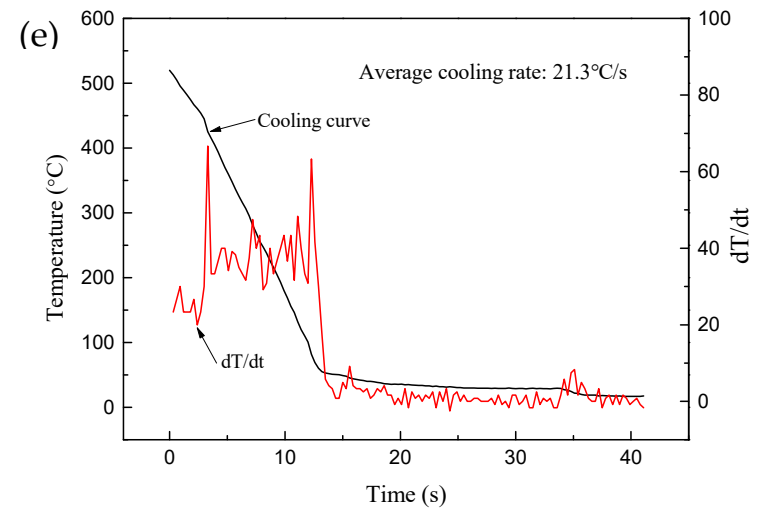

Figure 2. Cooling curves for the different sheets: (a) cooled in furnace, (b) coated with asbestos, (c) cooled in air, (d) cooled by wind, and (e) cooled by water.

\subsection{Influence of Different Cooling Rates on the Properties of Twin-Roll Casting 6061 Aluminum Alloy}

Figure 3 shows the mechanical properties of 6061 twin-roll casting sheets at room temperature under different cooling conditions. It can be seen from the figure that the cooling rate has no significant effect on the yield strength, but does on elongation and tensile strength. Furthermore, higher cooling rate can increase elongation and tensile strength of the alloy, which is consistent with the literature [20]. With the increase in cooling rate, the overall mechanical performance shows an increasing trend. Highest yield strength, tensile strength, and elongation of the sheet are found under wind-cooling and water-cooling conditions, which are $88 \mathrm{MPa}, 178 \mathrm{MPa}, 15 \%$ and $95 \mathrm{MPa}, 177 \mathrm{MPa}, 14 \%$, respectively.

The hardness curve of twin-roll casting sheet under different cooling conditions is shown in Figure 4. As can be seen from the figure, the hardness value of the twin-roll casting sheet shows an upward trend as the cooling rate increases. The hardness of the alloy is minimal with furnace cooling, about $52 \mathrm{HV}$, and the highest hardness of the alloy was obtained for the water-cooled condition, at about $95 \mathrm{HV}$. It can be inferred that the hardness of the 6061 twin-roll casting sheet can be increased with its cooling rate. 


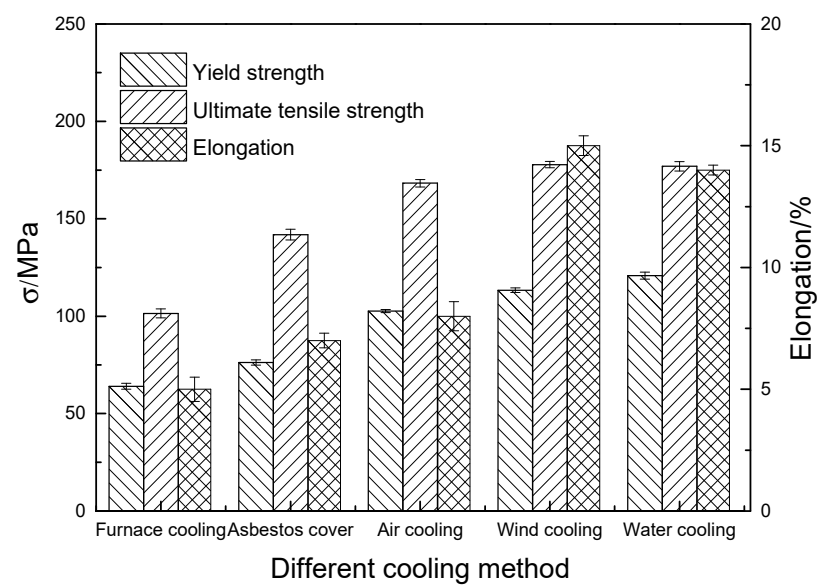

Figure 3. Mechanical properties of twin-roll casting sheets at different cooling rates.

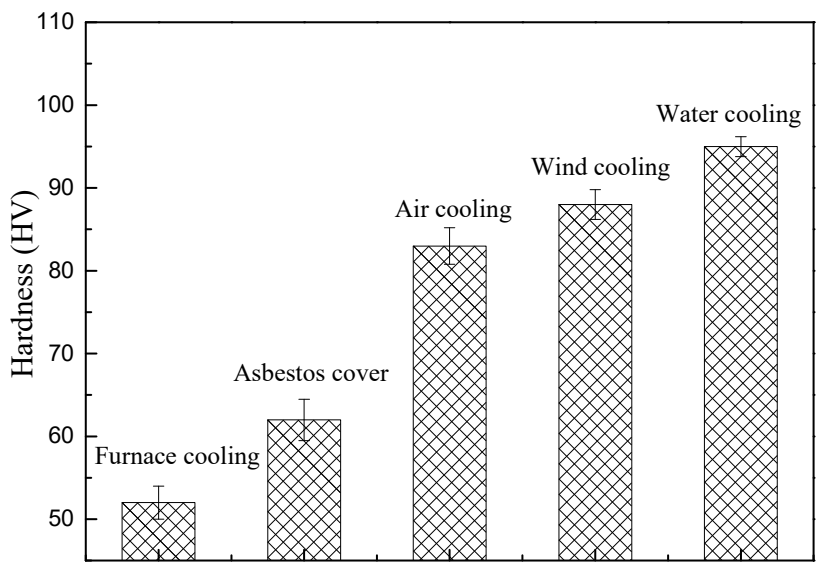

Different cooling methods

Figure 4. Hardness curves of twin-roll casting sheets using different cooling rates.

3.3. Influence of Different Cooling Rates on the Micro-Structure of Twin-Roll Casting 6061 Aluminum Alloy

Some studies show that the larger the crystallization interval, the more likely it is to cause composition segregation and composition inhomogeneity in the cast aluminum alloy [21,22]. The liquid temperature of 6061 aluminum alloy is $652{ }^{\circ} \mathrm{C}$, and solidus temperature was $582{ }^{\circ} \mathrm{C}$. The wide two-phase region would cause tissue unevenness and composition segregation during casting and rolling. During the rolling process of a thin sheet, the inside keeps a high temperature since the cooling rate at the outer surface of the sheet is faster. This causes coarse equiaxed grain at the center of thickness direction and fine grains at the outer edge, so that the interlayer appears and the overall grain size becomes uneven. Samples were performed in the rolling direction, and the sampling and observation sites are shown in Figure 5.

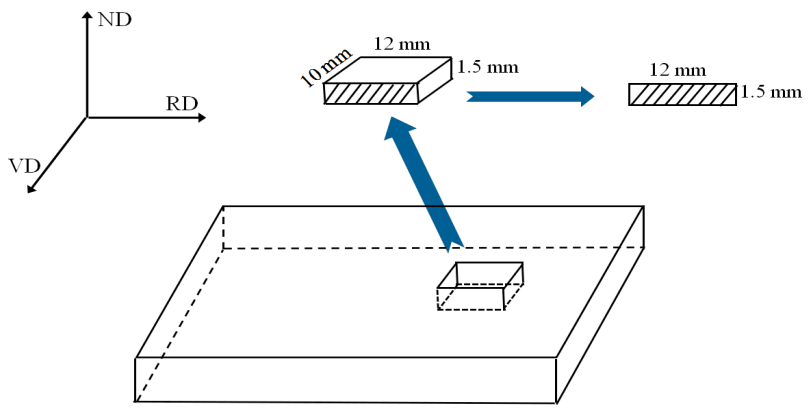

Figure 5. Schematic diagram of the sampling site. 
Figure 6 shows microstructures and grain sizes of 6061 aluminum alloy twin-roll casting sheets under different cooling conditions. As seen in Figure $6 \mathrm{a}$, the grain size of twin-roll casting sheets is large with furnace cooling conditions, because the alloy remains at a high temperature for a long time during furnace cooling [23]. Hence, recrystallization followed by grain growth occurs. Moreover, a large number of dispersed precipitates appear in the crystal, and the crystal grains are mostly elliptical or irregularly shaped polygons. The petal-like grains are found in the dendrite when cooled by asbestos-covering (shown in Figure 6b), and the grain size is smaller than that of the grain structure cooled by furnace. Figure $6 \mathrm{c}$ shows the microstructure obtained in an air-cooled state. The results indicate that the fine, equiaxed grains with uneven distribution were found in the air-cooled state. Small grains in the form of dendrites with larger petal-like grains interspersed, therefore, are observed for wind-cooled state. Compared to the three cooling methods described above, the grains under wind-cooling conditions are significantly coarse, as shown in Figure 6d. Figure 6e shows the twin-roll casting structure under water-cooled conditions. It was seen that fine grains were surrounded by equiaxed grains, the grain sizes were large and uneven, and the grain boundaries were coarse. It can be seen from the above description that there are big differences in the size and morphology of crystal grains in the 6061 twin-roll casting sheet under different cooling conditions. With an increase of cooling rate, finer crystal grains and less precipitates in the crystal were found in the twin-roll casting sheet.
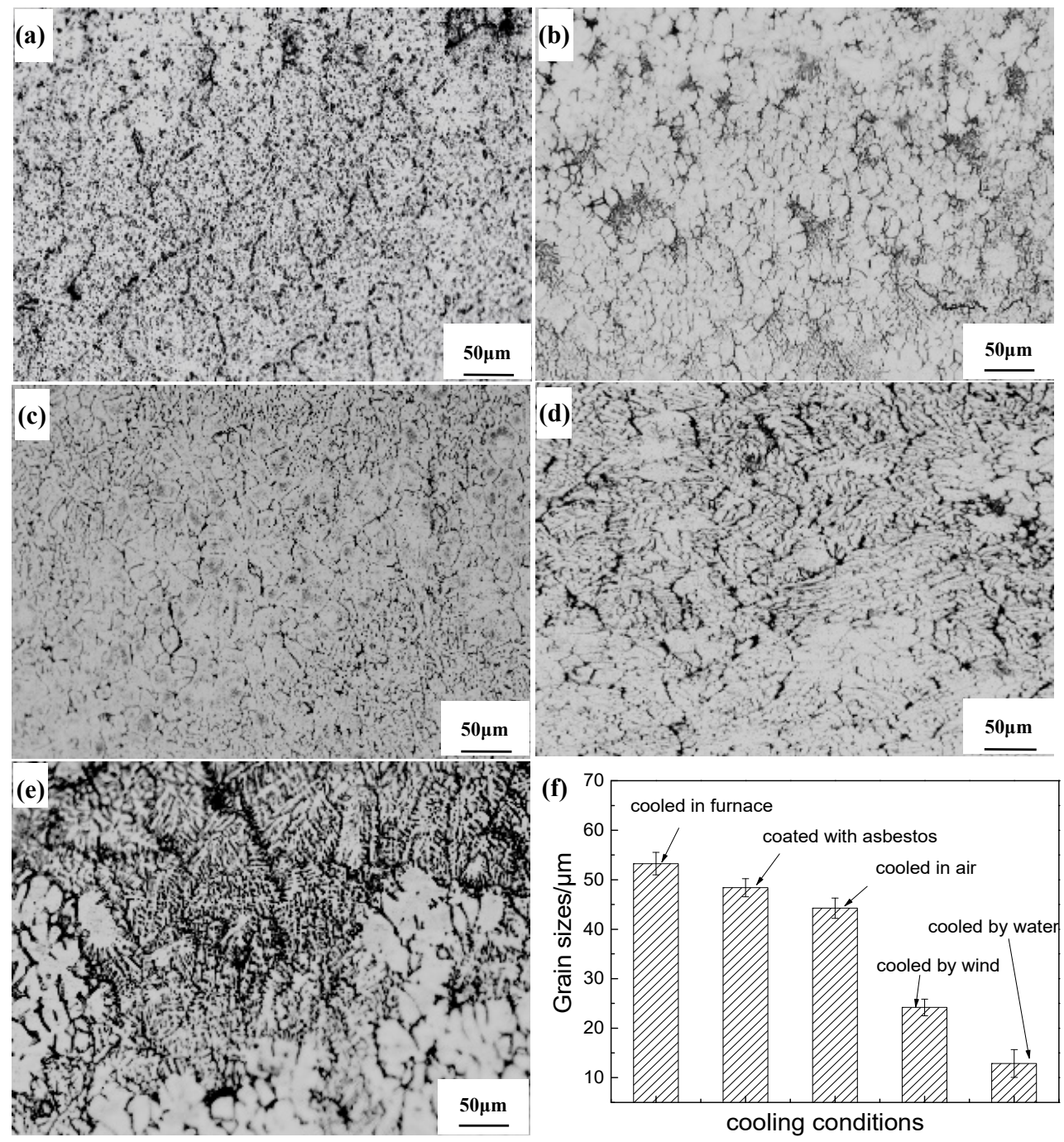

Figure 6. Microstructure of twin-roll casting sheets at different cooling rates: (a) cooled in furnace, (b) coated with asbestos, (c) cooled in air, (d) cooled by wind, (e) cooled by water and (f) average grain sizes. 
The distribution of precipitates in the sample can be observed by backscattering scanning electron microscopy, as shown in Figure 7 and Table 2. Figure 7a shows the microstructure of the alloy under furnace cooling conditions. It can be seen from the figure that the precipitation phases along the grain boundaries were distributed in an irregular polygon. Due to the high temperature in the furnace and lower cooling rate, the precipitation phase was redissolved, which is consistent with the results described in the literature [24].
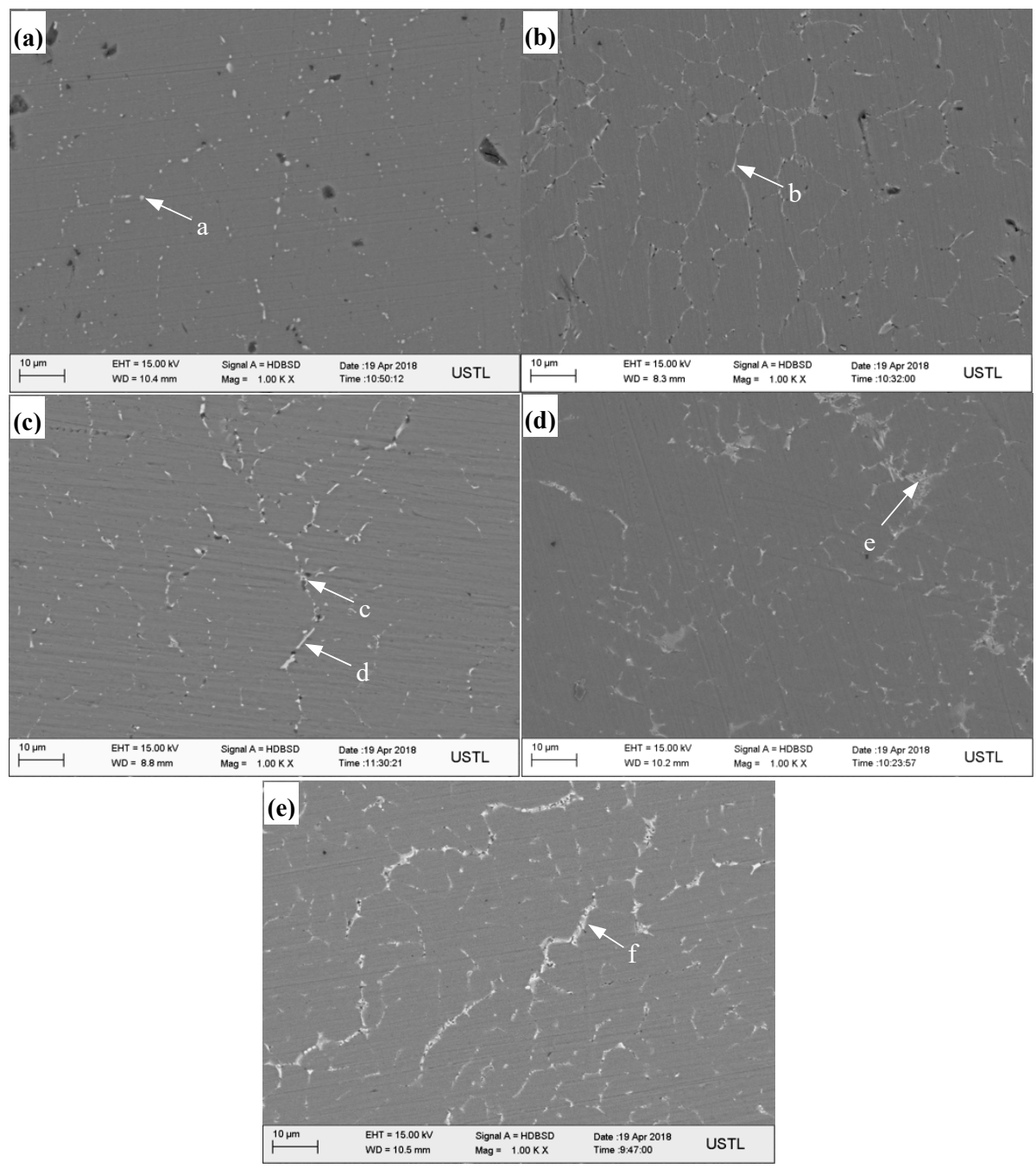

Figure 7. SEM morphology of twin-roll casting sheets at different cooling rates: (a) cooled in furnace, (b) coated with asbestos, (c) cooled in air, (d) cooled by wind, and (e) cooled by water.

Table 2. EDS analysis of the twin-roll casting sheets with different cooling rates.

\begin{tabular}{cccccccc}
\hline Elements/Atomic Fraction & $\mathbf{A l}$ & $\mathbf{S i}$ & $\mathbf{F e}$ & $\mathbf{M g}$ & $\mathbf{C u}$ & $\mathbf{N i}$ & $\mathbf{O}$ \\
\hline $\mathrm{a}$ & 87.33 & 1.63 & 3.51 & 0 & 0 & 2.96 & 4.57 \\
$\mathrm{~b}$ & 89.06 & 3.57 & 2.96 & 1.41 & 0 & 0 & 3.00 \\
$\mathrm{c}$ & 84.22 & 4.95 & 0.62 & 7.17 & 0 & 0 & 3.03 \\
$\mathrm{~d}$ & 70.79 & 8.63 & 5.02 & 7.22 & 0 & 0 & 8.33 \\
$\mathrm{e}$ & 72.73 & 10.45 & 3.29 & 7.38 & 0.76 & 0 & 5.41 \\
$\mathrm{f}$ & 74.65 & 9.75 & 4.37 & 5.80 & 1.48 & 0 & 3.95 \\
\hline
\end{tabular}

The precipitated phase has a discontinuous dot shape at the grain boundary, and a dispersed precipitate phase appears in the crystal. Twin-roll casting sheet with asbestos-covered cooling displays more precipitated phases, which are distributed in an irregular network along grain boundaries 
(Figure 7b). It was clearly observed that the second phase represented by the black dot was dispersed along the grain boundary, and a few bright white rod phases were also precipitated at the grain boundaries. There was almost no precipitate phase in the crystal, which is consistent with the results described in the literature [25].

Figure 7c shows that the grain size of the air-cooled sheet is inhomogeneous, and the precipitated phase is located along the grain boundary and is coarser than the previous two cooling methods (furnace cooling and asbestos covering). The precipitated phase mainly forms bright white rod phase and black dot as a second phase. The two phases are interspersed in the grain boundary, and there is no obvious precipitation phase in the crystal. Figure 7d is the SEM of a twin-roll casting sheet cooled by wind cooling. The fine grains were relatively uniform, and the precipitated phase was distributed along the grain boundaries, and a large-sized lamellar eutectic phase exists. The precipitated phase of the water-cooled sheet unevenly distributes along the grain boundary, and there is a coarse band-like eutectic structure. No precipitate phase exists in the crystal (Figure 7e). Due to the higher cooling rate, the precipitation phase accumulated at the grain boundary, so that the fracture was more likely to occur during stretching process [26,27].

The energy-dispersive spectrum (EDS) analysis (as shown in Table 2) of the twin-roll casting sheets with different cooling rates shows that the main components of black dot-like precipitates are $\mathrm{Al}, \mathrm{Mg}$, and $\mathrm{Si}$, and the main components of the bright white rod-like precipitates are $\mathrm{Al}, \mathrm{Fe}$, and $\mathrm{Si}$, the amellar and coarse ribbon-like precipitates consist of $\mathrm{Al}, \mathrm{Si}, \mathrm{Fe}, \mathrm{Mg}$, and $\mathrm{Cu}$. Combining EDS analysis with XRD analysis results (shown in Figure 8), it can be seen that the precipitates in the sheet consist mainly of black dot-shaped $\mathrm{Mg}_{2} \mathrm{Si}$ and a bright white rod-like or lamellar iron-rich phase.

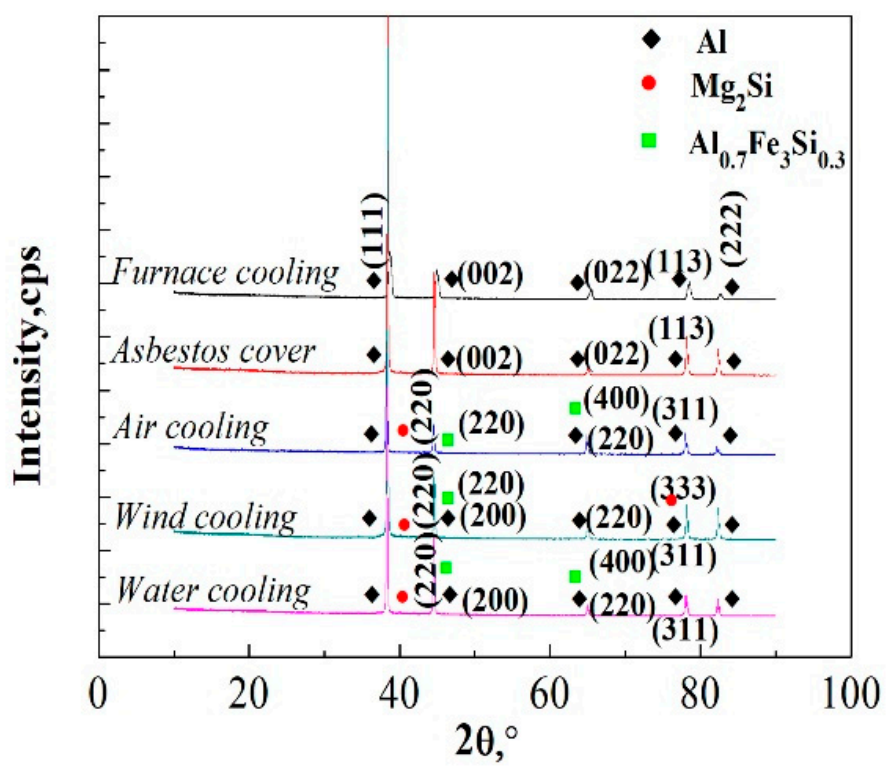

Figure 8. XRD analysis of twin-roll casting sheets with different cooling rates.

\subsection{Hall-Petch Relation of Strength and Grain Size}

As recognized, grain plays a significant role in the mechanical strength of metals, especially for the yield strength of $\mathrm{Al}$ alloys based on Hall-Petch (H-P) relation [28]. Figure 9 shows the profile plot of yield strength against the inverse square root of average grain size $\left(d^{-1 / 2}\right)$, where the slope represents the H-P slope $(K)$. The yield strength can be analyzed according to the H-P relation as below [29]:

$$
\sigma_{s}=\sigma_{0}+K d^{-\frac{1}{2}}
$$

where $\sigma_{s}$ is the yield strength, $\sigma_{0}$ is the friction stress when dislocations glide on the slip plane, $K$ is the magnitude of boundary obstacle against deformation propagation, and $d$ is the average grain size. 


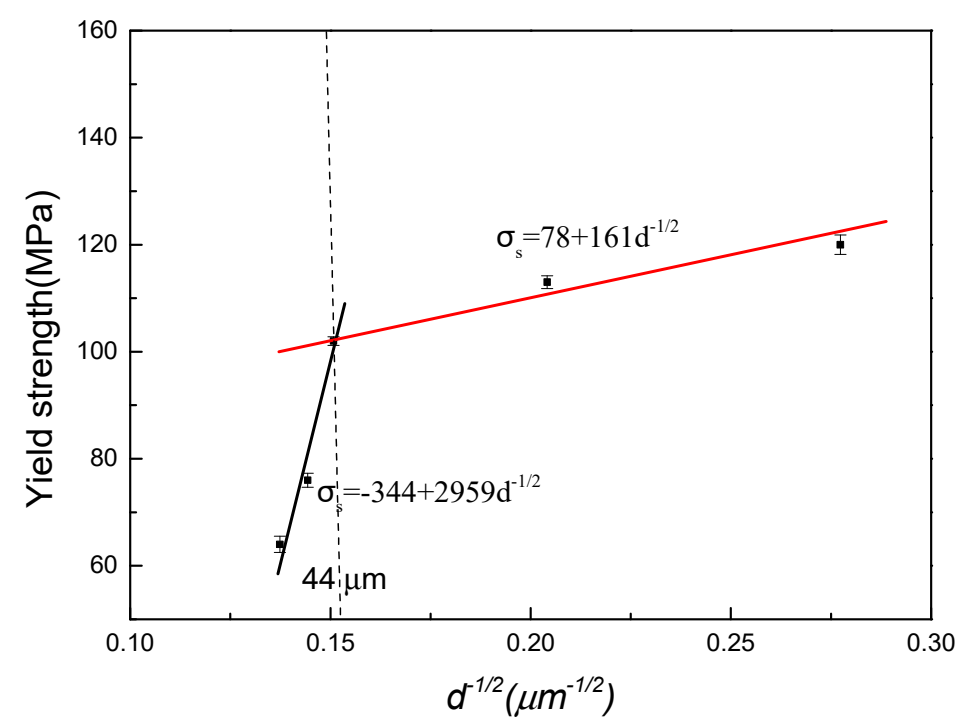

Figure 9. Hall-Petch relation of yield strength and the inverse square root of average grain size.

As shown in Figure 9, the fitted H-P curve is derived by two distinguished gradients for 6061 twin-roll casting sheet. The critical grain size is about $44 \mu \mathrm{m}$ for the transition from twinning to slip dominated flow, at which a distinct change in the H-P relation occurs. Therefore, fine grains can be defined as those of sizes smaller than the critical size $(<44 \mathrm{~mm})$, and coarse grains correspond to ones with larger grain sizes ( $>44 \mathrm{~mm}$ ), according to the distinguished deformation modes during tension. Based on the data in Figure 3, it can be calculated that $\sigma_{0}^{\prime}=344 \mathrm{MPa}$ and $K^{\prime}=2959 \mathrm{MPa}^{\prime} \mathrm{m}^{-1 / 2}$ have a grain size of $13-44 \mu \mathrm{m}$, while $\sigma_{0}^{\prime \prime}=78 \mathrm{MPa}$ and $K^{\prime \prime}=161 \mathrm{MPa}_{\mu \mathrm{m}}^{-1 / 2}$ have a grain size of $44-53 \mu \mathrm{m}$.

\subsection{Discussion}

From the above experimental results, it can be seen that different cooling methods can significantly change cooling rate, thereby affecting the morphology, grain morphology, and grain size of the material [30]. As cooling rate increases, the precipitation phase increases and grain size decreases. Moreover, the higher the cooling rate, the longer precipitated phase in the slab, and the more likely the second phase $\mathrm{Mg}_{2} \mathrm{Si}$ and the iron-rich phase are to occur. When the cooling rate was lower, a second phase, such as $\mathrm{Mg}_{2} \mathrm{Si}$, was found in a high temperature state; the solubility in the aluminum matrix was high, and the re-melting phenomenon occurs, so that the number of precipitated phases in the twin-roll casting sheet structure cooled by furnace was the smallest. However, the solubility of the Fe element in the aluminum matrix was low, and AlFeSi impurity phase was formed even at a high temperature, and there was no re-melting phenomenon. Simultaneously, the morphology of the second phase of $\mathrm{Mg}_{2} \mathrm{Si}$ changes from a continuous needle shape to an intermittent granular shape at a high temperature. Although the solubility of the AlFeSi phase in the matrix was low, the morphology of the precipitate phase mainly changed at different cooling rates. As the cooling rate increased, the iron-rich phase changed from a pellet in the high temperature state, to a rod shape or even a thick lath. Due to fine grain strengthening and precipitation strengthening, the strength of the material positively correlated with the cooling rate as a whole, i.e., the higher the cooling rate, the better the strength and elongation of the material. However, if the cooling rate of water cooling was too high, the precipitation phase along the grain boundaries was coarse, and the grain distribution was not uniform. In contrast, the grains in the air-cooled sample were finer and more uniform. Therefore, a strong plasticity of the 6061 twin-roll casting sheet under wind-cooled conditions is optimal (Figure 2e). In addition, the tensile strength of the asbestos-covered cooling twin-roll casting sheet did not conform to the above-mentioned cooling rate. It can be explained as the cooling rate is stable under the asbestos-covered cooling conditions without significant fluctuations. This cooling condition promoted uniform grains growth, while a uniform grain structure contributed to the strength of the material. 


\section{Conclusions}

(1) As the cooling rate increased, the tensile strength and elongation of the twin-roll casting sheet increased. The wind-cooled twin-roll casting sheet with an average cooling rate of $3{ }^{\circ} \mathrm{C} / \mathrm{s}$ showed the best overall performance. The yield strength at this time was $88 \mathrm{MPa}$, and a tensile strength of $178 \mathrm{MPa}$ and elongation of $15 \%$ were obtained for the wind-cooled twin-roll casting sheet. In addition, a quantitative $\mathrm{H}-\mathrm{P}$ relation was established to predict the yield strength of 6061 twin-roll casting sheet with different grain sizes and cooling rates.

(2) At higher cooling rates, more precipitates and second phase $\mathrm{Mg}_{2} \mathrm{Si}$ and iron-rich phase will appear.

(3) The morphology of the second phase of $\mathrm{Mg}_{2} \mathrm{Si}$ changed from a continuous needle shape to an. intermittent particle shape at high temperatures. As the cooling rate increased, the iron-rich phase changed from a pellet in a high temperature states to a rod shape or even a thick lath.

Author Contributions: Conceptualization, Z.X., S.L. and H.W.; methodology, Z.X.; software, Z.X. and S.W.; validation, Z.X. and S.W.; investigation, Z.X. and H.W.; resources, Z.X., X.C. and H.W.; writing-original draft preparation, Z.X.; writing-review and editing, Z.X., H.S. and S.W.; funding acquisition, S.L. and H.W. All authors have read and agreed to the published version of the manuscript.

Funding: This research was funded by National Natural Science Foundation of China (Grant number 51874172) and Research Fund for young teachers of University of Science and Technology Liaoning (Grant number 2019QN09).

Conflicts of Interest: The authors declare no conflict of interest.

\section{References}

1. Sajadifar, S.V.; Moeini, G.; Scharifi, E.; Lauhoff, C.; Bohm, S.; Niendorf, T. On the effect of quenching on postweld heat treatment of friction-stir-welded aluminum 7075 Alloy. J. Mater. Eng. Perform. 2019, 28, 5255-5265. [CrossRef]

2. Sajadifar, S.V.; Scharifi, E.; Weidig, U.; Steinhoff, K.; Niendorf, T. Effect of tool temperature on mechanical properties and microstructure of thermo-mechanically processed AA6082 and AA7075 aluminum alloys. J. Heat Treat. Mater. 2020, 75, 177-191. [CrossRef]

3. Sajadifar, S.V.; Scharifi, E.; Weidig, U.; Steinhoff, K.; Niendorf, T. Performance of thermo-mechanically processed AA7075 alloy at elevated temperatures-From microstructure to mechanical properties. Metals 2020, 10, 884. [CrossRef]

4. Zhong, H.; Paul, P.A.; Cao, L.; Estrin, Y. The influence of Mg/Si ratio and Cu content on the stretch formability of 6xxx aluminium alloys. Mater. Sci. Eng. A 2016, 651, 688-697. [CrossRef]

5. Rao, P.N.; Kaurwar, A.; Singh, D.; Jayaganthan, R. Enhancement in strength and ductility of Al-Mg-Si alloy by cryorolling followed by warm rolling. Procedia Eng. 2014, 75, 123-128. [CrossRef]

6. Lee, K.; Woo, K. Effect of the hot-rolling microstructure on texture and surface roughening of Al-Mg-Si series aluminum alloy sheets. Met. Mater. Int. 2011, 17, 689-695. [CrossRef]

7. Zhong, H.; Rometsch, P.; Estrin, Y. Effect of alloy composition and heat treatment on mechanical performance of 6xxx aluminum alloys. Trans. Nonferr. Met. Soc. Chin. 2014, 24, 2174-2178. [CrossRef]

8. Haga, T.; Kumai, S.; Watari, H. Strip casting of recycled aluminum alloys by a twin roll caster. Waste Biomass Valoriz. 2012, 3, 419-424. [CrossRef]

9. Ozturk, F.; Sisman, A.; Toros, S.; Kilic, S.; Picu, R.C. Influence of aging treatment on mechanical properties of 6061 aluminum alloy. Mater. Des. 2010, 31, 972-975. [CrossRef]

10. Neh, K.; Ullmann, M.; Oswald, M.; Berge, F.; Kawalla, R. Twin roll casting and strip rolling of several magnesium alloys. Mater. Today Proc. 2015, 2, S45-S52. [CrossRef]

11. Son, S.G.; Kim, H.K.; Cho, J.H.; Kim, H.W.; Lee, J.C. Differential speed rolling of twin-roll-cast $6 x x x$ al alloy strips and its influence on the sheet formability. Met. Mater. Int. 2016, 22, 1-10. [CrossRef]

12. Cho, J.H.; Kim, H.W.; Lim, C.Y.; Kang, S.B. Microstructure and mechanical properties of Al-Si-Mg alloys fabricated by twin roll casting and subsequent symmetric and asymmetric rolling. Met. Mater. Int. 2014, 20, 647-652. [CrossRef]

13. Shabestari, S.G.; Malekan, M. Thermal analysis study of the effect of the cooling rate on the microstructure and solidification parameters of 319 aluminum alloy. Can. Metall. Q. 2005, 44, 305-312. [CrossRef] 
14. Benjunior, B.; Ahmad, A.H.; Rashidi, M.M.; Reza, M.S. Effect of different cooling rates condition on thermal profile and microstructure of aluminium 6061. Procedia Eng. 2017, 184, 298-305. [CrossRef]

15. Jatimurti, W.; Alexander, B.; Wibisono, A.T. Effect of degassing time and cooling rate on microstructure and porosity of aluminum 6061 alloy using sand casting method. Mater. Sci. Forum 2019, 964, 124-129. [CrossRef]

16. Jiang, C.C.; Rui, Y.N. Thermodynamic behavior research analysis of twin-roll casting lead alloy strip process. Chin. J. Mech. Eng. 2017, 30, 352-362. [CrossRef]

17. Lai, Z.M.; Ye, D. Effect of cooling method and aging treatment on the microstructure and mechanical properties of Sn-10Bi solder alloy. J. Mater. Sci. Mater. Electron. 2015, 27, 1-10. [CrossRef]

18. Xu, C.L.; Jiang, Q.C. Morphologies of primary silicon in hypereutectic Al-Si alloys with melt overheating temperature and cooling rate. Mater. Sci. Eng. A 2006, 437, 451-455. [CrossRef]

19. Ou, M.G.; Zhang, S.; Song, H.C.; Liang, Y.L. Effects of different cooling methods on microstructure and mechanical properties of TC4 alloy. In Effects of Different Cooling Methods on Microstructure and Mechanical Properties of TC4 Alloy, Proceedings of the Chinese Materials Conference, Yinchuan, China, 6-12 July 2017; Springer: Singapore, 2017; pp. 539-547.

20. Eskin, D.; Du, Q.; Ruvalcaba, D.; Katgerman, L. Experimental study of structure formation in binary Al-Cu alloys at different cooling rates. Mater. Sci. Eng. A 2005, 405, 1-10. [CrossRef]

21. Grydin, O.; Stolbchenko, M.; Schaper, M. Deformation zone length and plastic strain in twin-roll casting of strips of Al-Mg-Si alloy. JOM 2017, 69, 1-5. [CrossRef]

22. Islam, M.N.; Boswell, B. Effect of cooling methods on cutting temperature, cutting force and hole quality in drilling of three ferrous alloys. J. Phys. Conf. Ser. 2016, 114, 12-22. [CrossRef]

23. Hichem, F.; Rebai, G. Study of dispersoid particles in two Al-Mg-Si aluminium alloys and their effects on the recrystallization. Appl. Phys. A 2015, 119, 1-5. [CrossRef]

24. Zhang, X.K.; Guo, M.X.; Zhang, J.S.; Zhuang, L.Z. Dissolution of precipitates during solution treatment of Al-Mg-Si-Cu alloys. Metall. Mater. Trans. B 2016, 47, 608-620. [CrossRef]

25. Gao, G.J.; He, C.; Li, Y.; Li, J.D.; Wang, Z.D.; Misra, R.D.K. Influence of different solution methods on microstructure, precipitation behavior and mechanical properties of $\mathrm{Al}-\mathrm{Mg}-\mathrm{Si}$ alloy. Trans. Nonfer. Met. Soc. Chin. 2018, 28, 839-847. [CrossRef]

26. Liu, S.D.; You, J.H.; Zhang, X.M.; Deng, Y.L.; Yuan, Y.B. Influence of cooling rate after homogenization on the flow behavior of aluminum alloy 7050 under hot compression. Met. Mater. Int. 2012, 18, 679-683. [CrossRef]

27. Zhang, Y.X.; Yi, Y.P.; Huang, S.Q.; Dong, F. Influence of quenching cooling rate on residual stress and tensile properties of 2A14 aluminum alloy forgings. Mater. Sci. Eng. A 2016, 674, 658-665. [CrossRef]

28. Hall, E.O. The deformation and ageing of mild steel: II characteristics of the luders deformation. Proc. Phys. Soc. B 1951, 64, 747-753. [CrossRef]

29. Wang, H.Y.; Xue, E.S.; Xiao, W.; Liu, Z.; Li, J.B.; Jiang, Q.C. Influence of grain size on deformation mechanisms in rolled Mg-3Al-3Sn alloy at room temperature. Mater. Sci. Eng. A 2011, 528, 8790-8794. [CrossRef]

30. Chen, R.; Shi, Y.F.; Xu, Q.Y.; Liu, B.C. Effect of cooling rate on solidification parameters and microstructure of Al-7Si-0.3Mg-0.15Fe alloy. Trans. Nonferr. Met. Soc. Chin. 2014, 24, 1645-1652. [CrossRef]

(C) 2020 by the authors. Licensee MDPI, Basel, Switzerland. This article is an open access article distributed under the terms and conditions of the Creative Commons Attribution (CC BY) license (http://creativecommons.org/licenses/by/4.0/). 